\title{
Pneumococcal vaccination in the United States: \\ Current recommendations and strategies to improve vaccination coverage
}

\author{
Cynthia G Whitney MD MPH
}

$S^{\prime}$ reptococcus pneumoniae is the most commonly identified cause of lower respiratory tract infections, a common cause of sepsis and meningitis, and a major cause of morbidity and mortality worldwide. In the United States, pneumococcal infections may cause more deaths each year than any other vaccine preventable disease (1). Mortality for pneumococcal pneumonia with bacteremia is about $20 \%$ among adults and as high as $40 \%$ among the elderly. In spite of the impressive public health burden of pneumococcal disease, vaccines against pneumococcus remain largely underutilized.

The recent emergence of drug-resistant $S$ pneumoniae places a new emphasis on the need for vaccination against pneumococcal infections. Clinically significant pneumococcal isolates with decreased susceptibility to penicillin were first identified in the United States in the 1970s but were uncommon until the early 1990s (2). Data from active, populationbased surveillance in the United States during 1995 and 1996 show that in some areas over $20 \%$ and $10 \%$ of isolates were no longer susceptible to penicillin and cefotaxime, respectively (3). Concurrent with the emergence of strains resistant to beta-lactams, pneumococci with decreased susceptibility to other classes of antimicrobial agents also have become more prevalent. The emergence of resistant strains makes empirical treatment decisions more challenging for clinicians; as pneu- mococcal infections become more difficult to treat, assuring that patients at risk receive adequate vaccination is more important than ever.

\section{IMMUNOGENICITY, EFFICACY AND SAFETY OF PNEUMOCOCCAL POIYSACCHARIDE VACCINES IN ADULTS}

Two 23-valent pneumococcal vaccines are currently commercially available from Merck and Company (New Jersey) (Pneumovax 23) and from Lederle Laboratories (New Jersey) (Pnu-Immune 23). These vaccines were licensed in the United States in 1983 and replaced an earlier 14-valent vaccine that was licensed in 1977 . The vaccines contain 23 purified pneumococcal capsular polysaccharide antigens: serotypes $1,2,3$, $4,5,6 \mathrm{~B}, 7 \mathrm{~F}, 8,9 \mathrm{~N}, 9 \mathrm{~V}, 10 \mathrm{~A}, 11 \mathrm{~A}, 12 \mathrm{~F}, 14,15 \mathrm{~B}, 17 \mathrm{~F}, 18 \mathrm{C}, 19 \mathrm{~A}$, $19 \mathrm{~F}, 20,22 \mathrm{~F}, 23 \mathrm{~F}$ and $33 \mathrm{~F}$. These serotypes comprise at least $85 \%$ to $90 \%$ of the serotypes that cause invasive (blood or other sterile site) infections in the United States (4) and include the serotypes of drug-resistant strains that most frequently cause invasive disease (5).

The vaccine's pneumococcal capsular polysaccharide antigens induce type-specific antibodies that augment pneumococcal opsonization, phagocytosis, and killing by leukocytes and other phagocytic cells. Pneumococcal capsular polysac-

Division of Bacterial and Mycotic Diseases, Respiratory Diseases Branch, National Center for Infectious Diseases, Centers for Disease Control and Prevention, Atlanta, Georgia

Correspondence: Dr Cynthia G Whitney, CDC Mailstop C-23, 1600 Clifton Road NE, Atlanta, Georgia 30333. Telephone 404-639-4727, fax 404-639-3970, e-mail cgw3@cdc.gov 
charide antigens induce antibodies mainly through $\mathrm{T}$ cell independent mechanisms. As a result, induction of antibodies is poor in children less than two years of age whose immune systems are immature. Additionally, polysaccharide vaccines do not induce immunological memory; therefore, booster responses (a rapid increase in antibody production that is much greater than the response to the first dose) after subsequent doses of vaccine do not occur. Among healthy young adults, however, at least $80 \%$ will develop an antigen-specific antibody response within two to three weeks of vaccination (6). Antibody responses in the elderly and in patients with alcoholic cirrhosis, chronic obstructive pulmonary disease (COPD), and insulin-dependent diabetes mellitus may be lower than those in healthy young adults $(1,6)$. Asplenic persons, and those with sickle cell disease and functional asplenia generally have antibody responses similar to those of healthy persons of similar ages (7). Antibody responses to pneumococcal vaccination are often absent or reduced in immunocompromised patients, including those with leukemia, lymphoma, multiple myeloma, chronic renal failure requiring dialysis, renal transplantation or nephrotic syndrome (1). Patients with Hodgkin's disease will have greater antibody responses if the vaccine is administered before splenectomy, radiation or chemotherapy. Antibody responses in persons with human immunodeficiency virus (HIV) infection may be related to the level of immunosuppression; HIV-infected persons with $\mathrm{CD} 4+\mathrm{T}$ lymphocyte counts lower than 500 cells/ $\mu \mathrm{L}$ often have lower antibody responses to pneumococcal vaccination than either HIV-infected persons with higher CD4 + T lymphocyte counts or persons who are not HIV-infected (8). Levels of antibodies to most pneumococcal antigens remain elevated for at least five years following vaccination in healthy adults.

Randomized trials of pneumococcal polysaccharide vaccine among young South African gold miners with a high rate of bacteremic and nonbacteremic pneumococcal infections found significant reduction in the occurrence of radiographically-confirmed pneumonia following vaccination $(9,10)$. However, it is not clear whether data from these trials can be generalized to the elderly. A postlicensure randomized trial in the United States did not demonstrate vaccine efficacy against pneumococcal pneumonia or bronchitis disease among elderly veterans (11), but the study lacked the statistical power to assess efficacy against invasive infection. A meta-analysis examining vaccine efficacy by combining the results of nine randomized, controlled clinical trials also did not demonstrate a protective effect for nonbacteremic pneumonia among persons in high risk groups (12).

Nonetheless, pneumococcal polysaccharide vaccine has been shown to be effective against bacteremic disease caused by organisms whose serotypes are contained in the vaccine. Effectiveness in case-control studies has ranged from $56 \%$ to $81 \%$ (4). A serotype prevalence study among persons older than five years of age demonstrated a $57 \%$ (95\% CI $45 \%$ to $66 \%)$ overall protective effectiveness against invasive infections caused by serotypes included in the vaccine (13). Vaccine effectiveness of $65 \%$ to $84 \%$ has also been demonstrated among immunocompetent persons 65 years of age or older and among persons with diabetes mellitus, coronary vascular disease, congestive heart failure, chronic pulmonary disease and anatomic asplenia. In addition, a meta-analysis of nine randomized controlled trials concluded that pneumococcal vaccine is efficacious in reducing the frequency of bacteremic pneumococcal pneumonia among low risk adults (12).

A recent cost effectiveness analysis (14) that considered pneumococcal bacteremia found that vaccination of people 65 years of age and older was cost saving; the intervention both reduced medical expenses and improved health. According to this analysis, vaccinating the 23 million elderly Americans who were unvaccinated in 1993 would have saved $\$ 194$ million and resulted in a gain of about 78,000 years of healthy life.

Pneumococcal polysaccharide vaccine is considered safe based on the experience since its licensure. One-third to onehalf of those receiving pneumococcal vaccine will experience mild side effects (such as pain, erythema or swelling at the site of injection), which generally persist less than $48 \mathrm{~h}$. Moderate systemic reactions (such as fever and myalgia) and more severe local reactions (such as Arthus-type reactions) are rare, as are severe systemic reactions (such as anaphylaxis). Local reactions may be more severe among those receiving a second dose of vaccine within two years of the first dose (15). The rate of occurrence of Arthus-type reactions among those recently vaccinated is unknown, but is probably rare. Studies have suggested that revaccination at least four years after the first dose, however, is not associated with an increased incidence of adverse side effects (4). Severe local reactions have also been associated with intradermal administration of vaccine; injections should be given intramuscularly or subcutaneously. No neurological disorders (such as Guillain-Barre syndrome) and no deaths have been associated with receiving pneumococcal vaccine. The safety of pneumococcal vaccine during the first trimester of pregnancy has not been evaluated. The safety and antibody response of pneumococcal vaccine does not decrease if given at the same time with other vaccines such as influenza, poliovirus, and the combined diphtheria, tetanus and pertussis vaccine (4).

\section{INDICATIONS FOR PNEUMOCOCCAL VACCINE}

Recent recommendations from the Advisory Committee on Immunization Practices (ACIP) provide a thorough review of those at higher risk for pneumococcal disease and describe indications for vaccination and revaccination (4). The ACIP is a panel of experts who meet periodically to discuss vaccination recommendations for the United States. Committee membership includes representatives from public health, clinical medicine, medical research and several professional organizations.

According to the ACIP recommendations, all persons 65 years of age and older should receive pneumococcal vaccine (Table 1). In addition, health care providers should vaccinate younger persons with certain chronic conditions (such as congestive heart failure, COPD, alcoholism, diabetes mellitus and asplenia), persons living in certain social settings (such as Alaskan Natives and certain American Indian populations), 


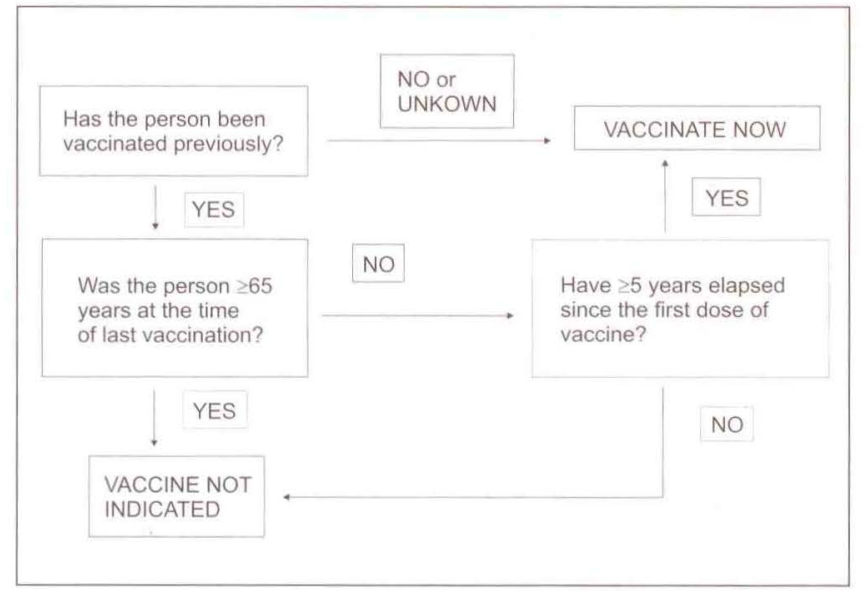

Figure 1) Algorithm for vaccinating patients aged 65 years or older with pneumococcal polysaccharide vaccine. Reprinted from reference 4

persons with immunosuppressing conditions (such as leukemia or HIV infection) and persons taking immunosuppressive therapy (such as prednisone).

In contrast to earlier recommendations, the new statement suggests that persons with an indication for pneumococcal vaccination should receive vaccine if their immunization history can not be determined (Figure 1). To avoid unnecessary doses, every patient should be given a vaccination record. However, in the absence of such records, health care providers should rely on patients' verbal history and not withhold pneumococcal vaccine for those patients with uncertain vaccination status.

The new statement also addresses the need for and timing of revaccination (Table 1, Figure 1). These recommendations were made on the basis of available data on the duration of immunity. Persons 65 years of age or older should receive a second dose of vaccine if the initial dose was at least five years earlier and was received before age 65 . For persons with functional or anatomical asplenia and immunocompromised persons over 10 years of age, a single revaccination should be provided five years or more after the first dose (revaccination recommendations vary for children younger than 10 years of age). Revaccination is not recommended for persons with other chronic medical conditions or for those in special environments and social settings.

\section{STRATEGIES TO IMPROVE VACCINATION COVERAGE}

The ACIP, the American Academy of Pediatrics, the American College of Physicians and the American Academy of Family Physicians have recommended the use of pneumococcal polysaccharide vaccine. In addition, several mechanisms are available to provide payment for pneumococcal vaccine for Medicare beneficiaries (persons eligible for Medicare include those 65 years of age or older). Medicare provides reimbursement for the vaccine and its administration (billing code G009) for individual out-patients, for groups of out-patients using roster billing, and for hospitalized patients independent of billing for other conditions.
TABLE 1

Recommendations of the Advisory Committee for Immunization Practices for use of pneumococcal vaccine

\begin{tabular}{|c|c|}
\hline Indications for vaccination & $\begin{array}{l}\text { Recommendations for } \\
\text { revaccination }\end{array}$ \\
\hline \multicolumn{2}{|l|}{ Immunocompetent persons } \\
\hline Aged 65 years or older & $\begin{array}{l}\text { Second dose recommended if pa- } \\
\text { tient received vaccine } 5 \text { years or } \\
\text { more previously and was less } \\
\text { than } 65 \text { years at the time of vac- } \\
\text { cination }\end{array}$ \\
\hline $\begin{array}{l}\text { Aged two to } 64 \text { years with } \\
\text { congestive heart failure or } \\
\text { cardiomyopathy }\end{array}$ & Not recommended \\
\hline $\begin{array}{l}\text { Aged two to } 64 \text { years with } \\
\text { chronic obstructive pulmonary } \\
\text { disease or emphysema }\end{array}$ & Not recommended \\
\hline $\begin{array}{l}\text { Aged two to } 64 \text { years with } \\
\text { diabetes mellitus }\end{array}$ & Not recommended \\
\hline $\begin{array}{l}\text { Aged two to } 64 \text { years with } \\
\text { alcoholism or chronic liver } \\
\text { disease including cirrhosis }\end{array}$ & Not recommended \\
\hline $\begin{array}{l}\text { Aged two to } 64 \text { years with } \\
\text { cerebrospinal fluid leaks }\end{array}$ & Not recommended \\
\hline $\begin{array}{l}\text { Aged two to } 64 \text { years with } \\
\text { functional or anatomic } \\
\text { asplenia }\end{array}$ & $\begin{array}{l}\text { If patient } 10 \text { years of age or older, } \\
\text { single revaccination } 5 \text { years or } \\
\text { more after previous dose }\end{array}$ \\
\hline $\begin{array}{l}\text { Aged two to } 64 \text { years living in } \\
\text { special environments or social } \\
\text { settings (eg Alaskan Native } \\
\text { sand certain American Indian } \\
\text { Populations }\end{array}$ & Not recommended \\
\hline \multicolumn{2}{|c|}{ Immunocompromised persons 10 years or older with } \\
\hline $\begin{array}{l}\text { Human immunodeficiency virus } \\
\text { infection }\end{array}$ & $\begin{array}{l}\text { Single revaccination if } 5 \text { years or } \\
\text { more have elapsed since first } \\
\text { dose }\end{array}$ \\
\hline Leukemia & Lymphoma \\
\hline $\begin{array}{l}\text { Chronic renal failure or } \\
\text { nephrotic syndrome }\end{array}$ & $\begin{array}{l}\text { Single revaccination if } 5 \text { years or } \\
\text { more have elapsed since first } \\
\text { dose }\end{array}$ \\
\hline $\begin{array}{l}\text { Immunosuppressive therapy } \\
\text { including steroids }\end{array}$ & $\begin{array}{l}\text { Single revaccination if } 5 \text { years or } \\
\text { more have elapsed since first } \\
\text { dose }\end{array}$ \\
\hline $\begin{array}{l}\text { Organ or bone marrow } \\
\text { transplant }\end{array}$ & $\begin{array}{l}\text { Single revaccination if } 5 \text { years or } \\
\text { more have elapsed since first } \\
\text { dose }\end{array}$ \\
\hline
\end{tabular}

Reprinted from reference 4

In spite of multiple endorsements and the availability of payment, the vaccine remains widely underused. Self-reported data from the 1995 Behavioral Risk Factor Surveillance System indicates that only $36 \%$ of respondents age 65 years or older recalled ever receiving pneumococcal vaccine (16). As low as this coverage figure is, it represents a $7 \%$ increase for pneumococcal vaccine compared with rates of coverage in 1993. Non-Hispanic blacks, who are at higher risk for pneumococcal disease than Hispanics or non-Hispanic whites, were less likely to report ever receiving pneumococcal vaccine than either Hispanics or non-Hispanic whites. Barriers to vaccination among adults have included missed opportunities for 
vaccination during contacts with health care providers in clinics and hospitals, lack of delivery systems outside the routine health care system, fears concerning adverse events following vaccination, a lack of awareness of the seriousness of pneumococcal diseases and a lack of awareness of the benefits of pneumococcal vaccination, especially against bacteremic disease.

Several strategies exist for overcoming these barriers and increasing vaccine coverage in patient populations at higher risk for pneumococcal disease. Strategies at the organizational level, such as standing orders that remove the need for a specific physician's order, are the most effective means for increasing vaccination rates (17). Standing orders in hospitals have been shown to increase markedly the coverage rates for pneumococcal vaccination and influenza vaccination, and the Health Care Financing Administration has approved the use of standing orders to provide pneumococcal vaccine for Medicare recipients. Standing orders can be designed to ensure vaccination before discharge from hospitals and to ensure vaccination on admission in nursing homes and other long term care facilities. Recent epidemics of pneumococcal infection in long term care facilities where less than $5 \%$ of residents had been vaccinated highlight the importance of pneumococcal vaccination for institutionalized high risk persons (18).

In one New York hospital, the use of standing orders resulted in a pneumococcal vaccine coverage rate of $78 \%$ in a study population compared with $0 \%$ in a control group (19). The use of standing orders for influenza vaccination in community hospitals in Minnesota resulted in vaccine coverage of $40 \%$ compared with $17 \%$ and $9.6 \%$ coverage for hospitals that used physician chart reminders and educational efforts, respectively (20).

Vaccinating hospitalized patients may be an effective means of reaching those at highest risk for pneumococcal infection. A study of persons with serious pneumococcal infections found that most had been hospitalized within the past four years, yet few had received pneumococcal vaccine (21). According to this study, vaccinating approximately 100 patients before hospital discharge would prevent a single patient from returning to the hospital with pneumonia. The cost of this vaccination strategy was estimated to be approximately one-third the cost of hospital care for patients readmitted with pneumonia.

Other strategies to improve coverage rates include systems to track immunizations within clinics and physician reminder systems. Tracking systems involve identifying the total number of patients at risk for pneumococcal disease and maintaining lists showing the proportion of vaccinated patients. Reminder systems can consist of charts, computer prompts or preventive health checklists that remind physicians to review the need for pneumococcal vaccination for each patient. Medical staff can also identify and label the records of those patients who should receive vaccine. Several studies have shown that the use of tracking systems, preventive health checklists and computer reminder systems can increase pneumococcal vaccination rates (4).

Physicians can also review the need for immunization in individual patients based on age. Because many patients 50 to 64 years of age have chronic illnesses, a visit at around age 50 should include an assessment of the need for pneumococcal vaccination. A similar assessment should occur for adolescents 11 to 12 years of age during a clinic visit for routine immunizations.

Finally, special outreach clinics held in health departments, health centres, nursing homes and other settings can provide the means to vaccinate populations that may otherwise be difficult to reach or are underserved. The need for pneumococcal vaccination can be assessed and vaccine provided to persons attending mass vaccination clinics for influenza because many of the indications for pneumococcal vaccine are similar to those for influenza vaccine, and the two vaccines may be administered at the same time at different injection sites without an increase in side effects or decreased antibody response to either vaccine. A program in California illustrated that providing pneumococcal vaccine to persons attending influenza vaccine clinics was an effective means of delivery (22). Providing vaccine during the clinic was more effective than promoting the vaccine among persons at the influenza clinic but referring them elsewhere for pneumococcal vaccine.

\section{THE FUTURE: DEVELOPMENT OF PNEUMOCOCCAL CONJUGATE VACCINES}

Vaccines are in development that promise to provide longer term immunity and better antibody responses in young children. These vaccines consist of capsular polysaccharides that are covalently coupled to a carrier protein, a structure similar to that of the vaccine currently used in infants against Haemophilus influenzae type $\mathrm{b}$. By conjugating polysaccharide to a protein, the immunological responses become $\mathrm{T}$ cell dependent resulting in higher antibody levels in infants and production of memory B cells ready for booster responses - rapid and dramatic increases in antibody levels with later doses of vaccine. Preliminary results from phase one and phase two trials indicate that the vaccines are safe and immunogenic in in fants and young children (4), and multicentre trials of efficacy in children are ongoing.

Until conjugate pneumococcal vaccines are shown to be effective and licensed for use, public health professionals and clinicians should continue to promote the use of pneumococcal polysaccharide vaccine. Pneumococcal polysaccharide vaccine has been shown to be cost effective and safe, yet it remains widely underused. Strategies such as the use of standing orders in hospitals and nursing homes, and providing pneumococcal vaccine during influenza clinics can markedly improve vaccination coverage. In this time of emerging drug-resistant pneumococci, the use of such programs has become more important than ever.

\section{REFERENCES}

1. Fedson DS, Musher DM. Pneumococcal vaccine. In: Plotkin SA, Mortimer EA Jr, eds. Vaccines, 2nd edn. Philadelphia: WB Saunders, 1993:517-63.

2. Breiman RF, Butler JC, Tenover FC, Elliott JA, Facklam RR. Emergence of drug-resistant pneumococcal infections in the United States. JAMA 1994;271:1831-5.

3. Cetron MS, Breiman RF, Jorgensen JH, et al. Multi-site population-based surveillance for drug-resistant Streptococcus 
pneumoniae [Abstract C-2831]. The 97th General Meeting, American Society for Microbiology. Washington, May 4 to 8 , 1997. (Abst C-2831)

4. Centers for Disease Control and Prevention. Prevention of pneumococcal disease: recommendations of the Advisory Committee on Immunization Practices (ACIP). Morb Mortal Wkly Rep 1997;46(No. RR-8).

5. Butler JC, Hofmann J, Cetron MS, Elliott JA, Facklam RR, Breiman RF. The continued emergence of drug-resistant Streptococcus pneumoniae in the United States: an update from the Centers for Disease Control and Prevention's Pneumococcal Sentinel Surveillance System. J Infect Dis 1996;174:986-93.

6. Musher DM, Luchi MJ, Watson DA, Hamilton R, Baughn RE. Pneumococcal polysaccharide vaccine in young adults and older bronchitics: determination of IgG response by ELISA and the effect of absorption of serum with non-type-specific cell wall polysaccharide. J Infect Dis 1990;161:728-35.

7. Ammann AJ, Addiego J, Wara DW, Lubin D, Smith WB, Mentzer WC. Polyvalent pneumococcal-polysaccharide immunization of patients with sickle-cell anemia and patients with splenectomy. N Engl J Med 1977;297:897-900.

8. Rodriquez-Barradas MC, Musher DM, Lahart C, et al. Antibody to capsular polysaccharides of Streptococcus pneumoniae after vaccination of human immunodeficiency virus-infected subjects with 23-valent pneumococcal vaccine. J Infect Dis 1992;165:553-6.

9. Smit P, Oberholzer D, Hayden-Smith S, Koornhof HJ, Hilleman MR. Protective efficacy of pneumococcal polysaccharide vaccines. JAMA 1977:238:2613-6.

10. Riley ID, Tarr PI, Andrews M, et al. Immunisation with a polyvalent pneumococcal vaccine. Reduction of adult respiratory mortality in a New Guinea Highlands community. Lancet 1977;i:1338-41.

11. Simberkoff MS, Cross AP, Al-Ibrahim M, et al. Efficacy of pneumococcal vaccine in high risk patients. Results of a Veterans Administration cooperative study. N Engl J Med 1986;315:1318-27.
12. Fine MJ, Smith MA, Carson CA, et al. Efficacy of pneumococcal vaccination in adults. A meta-analysis of randomized controlled trials. Arch Intern Med 1994;154:2666-77.

13. Butler JC, Breiman RF, Campbell JF, Lipman BB, Broome CV, Facklam RR. Pneumococcal polysaccharide vaccine efficacy. An evaluation of current recommendations. JAMA 1993;270:1826-31.

14. Sisk JE, Moskowitz AJ, Whang W, et al. Cost-effectiveness of vaccination against pneumococcal bacteremia among elderly people. JAMA 1997;278:1333-9.

15. Borgono JM, McLean AA, Vella PP, et al. Vaccination and revaccination with polyvalent pneumococcal polysaccharide vaccines in adults and infants. Proc Soc Exp Biol Med 1978; $157: 148-54$

16. Centers for Disease Control and Prevention. Pneumococcal and influenza vaccination levels among adults aged $\geq 65$ years - United States, 1995 . Morb Mortal Wkly Rep 1997:46:913-9.

17. Gyorkos TW, Tannenbaum TN, Abrahamowicz M, et al. Evaluation of the effectiveness of immunization delivery methods. Can J Public Health 1994;85(Suppl 1):S14-S30.

18. Centers for Disease Control and Prevention. Outbreaks of pneumococcal pneumonia among unvaccinated residents in chronic-care facilities - Massachusetts, October 1995, Oklahoma, February 1996, and Maryland, May-June 1996. Morb Mortal Wkly Rep 1997;46:60-2.

19. Klein RS, Adachi N. An effective hospital-based pneumococcal immunization program. Arch Intern Med 1986;146:327-9.

20. Crouse BI, Nichol K, Peterson DC, Grimm MB. Hospital-based strategies for improving influenza vaccination rates. J Fam Pract 1994:38:258-61.

21. Fedson DS, Harward MP, Reid RA, Kaiser DL. Hospital-based pneumococcal immunization. Epidemiologic rationale from the Shenandoah study. JAMA 1990;264:1117-22.

22. Centers for Disease Control and Prevention. Pneumococcal immunization program - California, 1986-1988. Morb Mortal Wkly Rep 1989;38:517-9. 


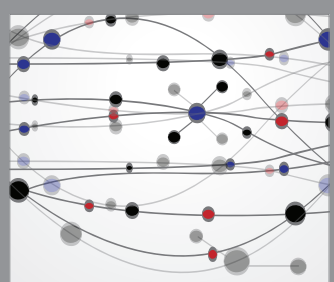

The Scientific World Journal
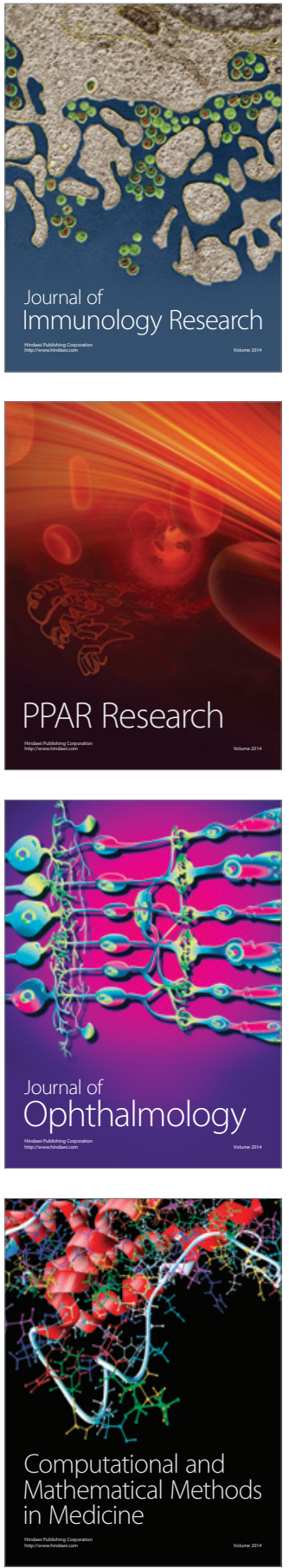

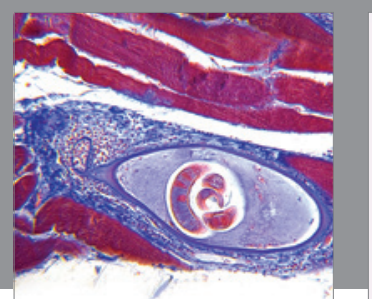

Gastroenterology Research and Practice

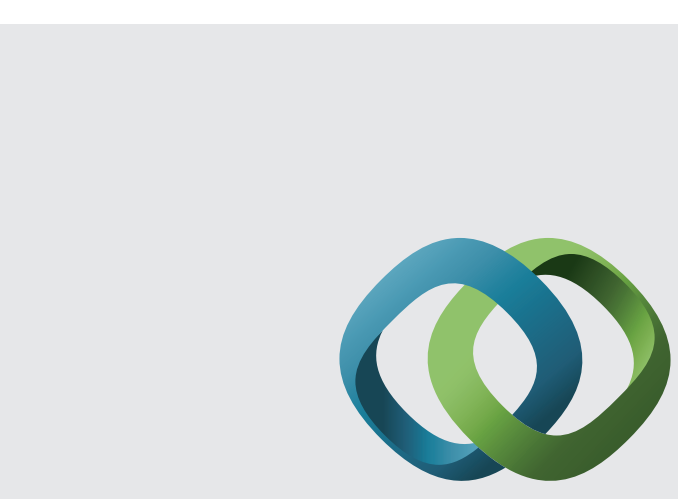

\section{Hindawi}

Submit your manuscripts at

http://www.hindawi.com
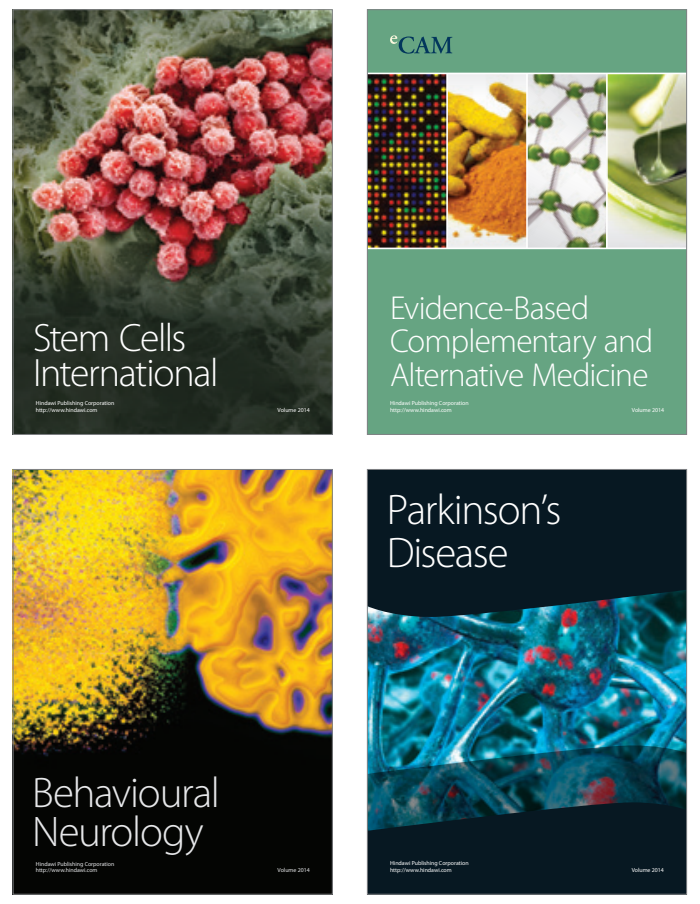
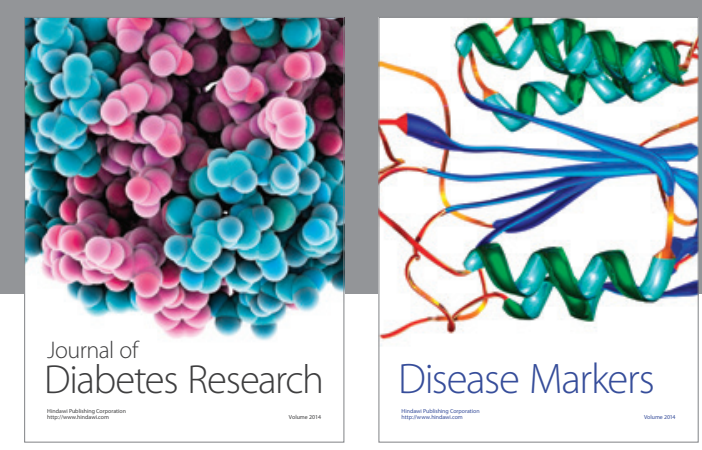

Disease Markers
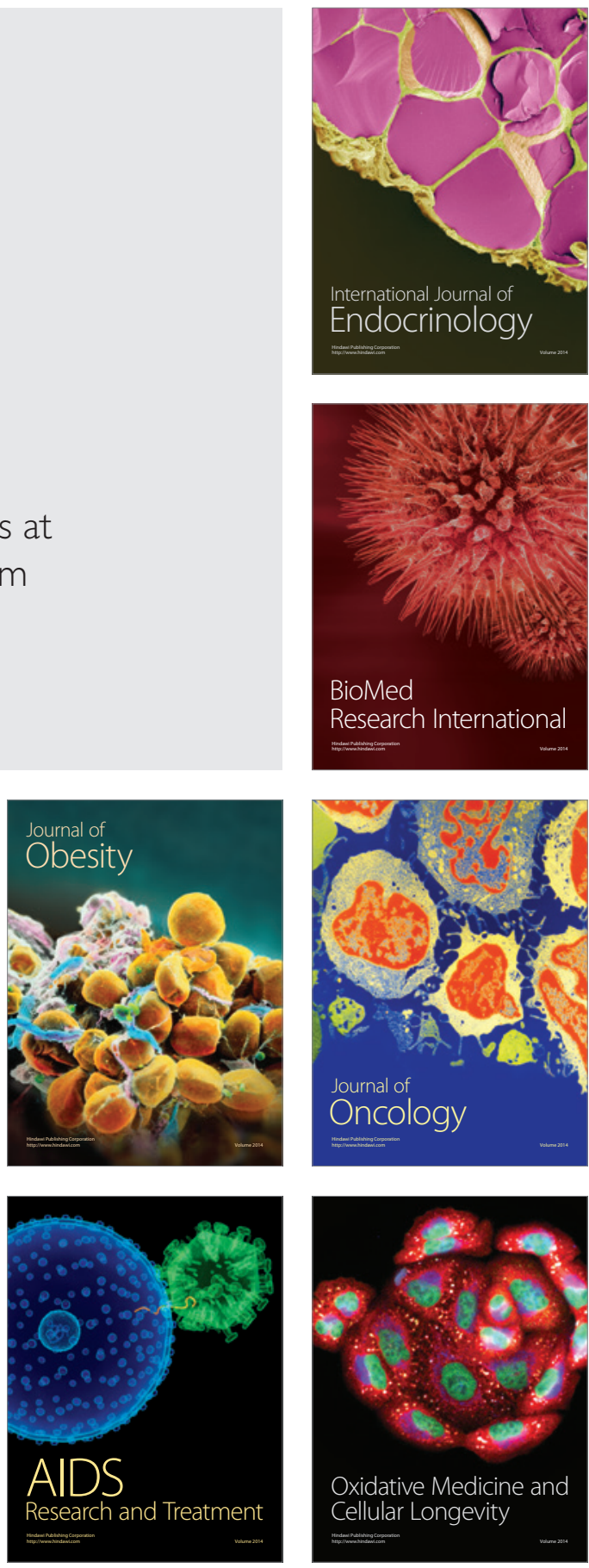